\title{
From Talk to Action: Experiencing Interlocution in Developmental Interventions
}

\author{
Annalisa Sannino \\ University of Salerno, Italy
}

\begin{abstract}
This article explores how to analyze and conceptualize the dynamics through which conversations in Change Laboratory research interventions lead to envisioning and implementing material changes in activities. Leont'ev's concept of personal sense is used as a theoretical lens for tracing these dynamics and to provide a means to relate local conversations to overall transformation of professional practices. In addition, the article tests the potential of Vasilyuk's theory of experiencing and Trognon's interlocutionary logic for analyzing Change Laboratory conversations from the point of view of how talk is experienced by the interlocutors. Experiencing is seen as a dialogical process that connects ongoing conversations and future-oriented actions, and through which interlocutors overcome critical situations. The analysis of Change Laboratory discussions in a Finnish middle school provides ground for looking at Change Laboratory as a research setting and a practice of intervention which can enrich our understanding of how change unfolds through discourse. The article concludes that interventions such as Change Laboratory could benefit from identifying systematic procedures for facilitating experiencing and interlocution. Within the perspective of seeking such methodological procedures, the article opens up a discussion on complementarities and possibilities of integration between the Change Laboratory and another interventionist approach called the Clinic of Activity.
\end{abstract}

\section{INTRODUCTION}

This article analyzes how discussions ${ }^{1}$ within research interventions affect material actions in activities. The article focuses in particular on one type of research intervention called Change Laboratory (Virkkunen, Engeström, Helle, Pihlaja, \& Poikela, 1997). Change Laboratories are tools for transforming work, used by researchers within the broad theoretical and methodological framework of developmental work research (Y. Engeström, Lompscher, \& Rückriem, 2005).

\footnotetext{
${ }^{1}$ In this article the terms interlocution, discussion, and conversation are used interchangeably to refer to the use of language during face-to-face interactions in research interventions.

Correspondence should be sent to Annalisa Sannino, University of Salerno, Department of Education, via Ponte don Melillo, 1, 84084 Fisciano (SA), Italy. E-mail: ansannin@unisa.it
} 
This is an approach developed in Finland since the 1980s, which is now also spreading to other countries (Hill, Capper, \& Wilson, 2007).

The Change Laboratory is a method of intervention based on Vygotsky's (1978) method of double stimulation. The central idea behind the Change Laboratory is that educational and work practices can develop through collective, cognitive, and material reconceptualization of the object of the activity. The reconceptualization process is mainly mediated by videotaped materials and theoretical models used as stimuli for discussing and redesigning practices. Through the process of double stimulation, participants in the intervention face and work out contradictions of their own practices. ${ }^{2}$ This article addresses the following methodological questions: How does one analyze the way participants articulate and reconceptualize the object of their practice in Change Laboratory discussions? How does one conceptualize ways in which Change Laboratory conversations lead participants to invest in the object of their practice with new motivating power?

The article is structured in seven sections. The first section provides a brief presentation of the method of the Change Laboratory. Then it discusses Leont'ev's concept of personal sense as a theoretical tool for explaining how conversations in Change Laboratory lead participants to envision and engage in implementing change in their practice. It is argued that individuals reconceptualize the object of their practice by gradually developing their personal sense of it in the course of discussions with others. Personal sense is the individual's perspective on both the ongoing situated interaction and on the object of the activity, which is discussed often in conflictual ways in Change Laboratory.

The second section of the article elaborates the theoretical framework. On one hand, I use Vasilyuk's (1988) theory of experiencing, developed within the general framework of culturalhistorical activity theory. On the other hand, I draw on a pragmatic approach to discourse studies called interlocutionary logic (Trognon, 1999). Transformations of educational and work practices through developmental research interventions such as Change Laboratory are achieved by means of discussions and negotiations between multiple parties. The involvement of the participants in the process of designing and implementing innovations in their own practice depends to a great extent on the way they experience the conversations during the intervention sessions. The joint use of Vasilyuk's theory and of interlocutionary logic is an attempt to analyze discussions in Change Laboratory from the point of view of the interlocutors' experiences.

The third section clarifies the role of experiencing as a collective and discursive process, which prepares individuals to act for changing their practices. This preparation is a joint reflective effort, which at same time brings and supports individuals to face conflictual motives with regard to their practices.

The fourth and fifth sections present and analyze an excerpt from discussions in a Change Laboratory, respectively. The data have been collected during an 11-week Change Laboratory intervention with the teachers in a middle school in Finland. ${ }^{3}$ The school is located in a

\footnotetext{
${ }^{2}$ These developmental interventions are different from the design experiments discussed in Brown (1992); Collins (1992); and more recently, for example, in van der Akker, Gravemeijer, McKenney, and Nieveen (2006). A brief comparison between Change Laboratoty and design experiments is included in Y. Engeström (2007).

${ }^{3}$ The data used in this article were originally collected in a intervention research project, financed by the Board of Education of the City of Helsinki and conducted in a middle school in Helsinki, Finland, in 1998 and 1999. The principal investigator of the project was Yrjö Engeström. The other members of the project group were Ritva Engeström, Pirjo Korvela, and Arja Suntio. The segments of the original data used in this article have been previously analyzed by the original researchers and the results of their analysis have been published (Y. Engeström, Engeström, \& Suntio, 2002a).
} 
disadvantaged area in Helsinki with a high rate of unemployment and large percentage of immigrants and refugees compared to other areas in Helsinki. The analysis demonstrates that the chosen conceptual framework is a viable basis for studying the trajectories from talk to material actions in activities. Change Laboratory also appears from the analysis as a research setting and a practice of intervention that can enrich our understanding of how change unfolds through discourse. It is argued, however, that a condition for pursuing this type of empirical analyses is to work out systematic procedures to facilitate experiencing and interlocution.

The sixth section looks for such systematic procedures in another interventionist approach within the broad framework of activity theory. I examine the possibility of using the method of the Clinic of Activity to expand the potential of Change Laboratory. Key procedures of the two research methods are compared and complementarities are highlighted.

The seventh section points out that the adoption of an historical perspective on both individuals and activities is a condition for the hybridization of the two methods. Discursive processes of experiencing and change initiatives that derive from them can be understood by taking into account the role of past events while individuals negotiate future orientations in their work activities.

This article contributes to discourse studies and to activity theoretical methods of intervention research. The contribution to the field of discourse studies is made by pointing out the material consequences that discussions in Change Laboratory can have on transforming professional practices. Alessandro Duranti (2007) discussed how agency is both codified and realized in language. Duranti's perspective is innovative because it points out the centrality of agency for revealing how language constructs social reality. The phenomena of social reality that the author takes into account are, however, limited to the construction of individual social identity. This article, although it shares a similar pragmatic view on language, provides a different perspective. It shows that it can be useful to also analyze discursive agency as embedded in collective transformations of activities.

The second contribution of this article pertains to methods of research interventions developed within activity theory. Although Change Laboratory is a powerful method for enhancing expansive transformations of activities, it has limitations that may be overcome by focusing on issues of experiencing and by integrating complementary resources from the Clinic of Activity. Research interventionists and participants in research interventions would benefit from such expansions for conducting and designing Change Laboratories.

\section{THE ROLE OF PERSONAL SENSE IN ENVISIONING AND IMPLEMENTING CHANGE}

How do interactions during interventions such as the Change Laboratory lead to practical transformations in a workplace? After a brief presentation of the method of the Change Laboratory, I take up Leont'ev's (1978) concept of personal sense as a lens for tracing the dynamics that lead envisioning and implementing change in Change Laboratory interactions.

Yrjö Engeström gave me access to and permission to use the data, in the spirit of the research-ethical rules of the American Psychological Association, which emphasize the importance of data sharing and state that "after research results are published, psychologists do not withhold the data on which their conclusions are based from other competent professionals who seek to verify the substantive claims through reanalysis and who intend to use such data only for that purpose, provided that the confidentiality of the participants can be protected and unless legal rights concerning proprietary data preclude their release" (APA 6.25). 
The Change Laboratory is an interventionist method developed and used within the framework of activity theory to promote change in workplaces. Interventionist researchers pursue this aim by initiating cycles of discussions in which participants with the help of a number of artifacts reconceptualize the object of their work and invest it with new meaning. The method implies the following steps: After a period of preliminary ethnographic inquiries, the participants meet in object-oriented Change Laboratory sessions that typically last for 2 hours and occur once a week, for a period of 6 to 12 weeks. One or two follow-up intervention sessions are commonly conducted after a period of experimentation with the new solutions identified in the course of the weekly Change Laboratory encounters. The process may be renewed cyclically for several years.

During the Change Laboratory sessions, participants and researchers rely on a set of representational devices for jointly analyzing disturbances in the daily work practices and for developing new practices. The main tools they use are writing surfaces, such as whiteboards, which allow them to take notes of the key points stemming from the discussions. There are three sets of surfaces. One is called "mirror" and serves to bring in the discussions critical events or also innovative solutions from the workplace. These experiences are reproduced in general by playing videotaped episodes or interviews filmed during the preliminary ethnographic enquiry, by examing documents, or by inviting into the laboratory sessions key figures involved in the activity the group is developing (e.g., customers, patients, students, etc.). Another set of surfaces is called "model and vision." These are used for elaborating conceptual models of the activity under scrutiny to analyze its inner contradictions. Y. Engeström's (1987) well-known triangular model of an activity system is often used, but it is also common that the practitioners themselves elaborate their own conceptual models (see, e.g., Y. Engeström, Engeström, $\&$ Kerosuo, 2003). The third set of surfaces used in the Change Laboratory are called "ideas and tools" and are located between the two other sets of surfaces. The denomination "ideas and tools" refers to initial conceptualizations which require further elaboration and discussions. This surface is used as an intermediate "empty" stage between the experiential mirror and the theoretically structured model/vision to capture emerging ideas and representations in progress.

Each set of surfaces is also used as a "time travel" device for tracing the historical roots of the activity and for identifying the sources of its contradictions. For that purpose, participants in Change Laboratory sessions move from current problems in their activity to problems experienced in the past. They model their activity as it used to be in the past and then move on to elaborate models of the current activity and its contradictions. The next step consists in designing a future model for the activity system and a number of concrete partial solutions connected to that vision, to be implemented and monitored in practice. ${ }^{4}$

Participants analyze and redesign their practice in dialogue with others, focusing on an expansive redefinition of their object:

A thing out there in the environment can only become the object of an activity when it meets the need of the actors and is invested with meaning and motivating power. The object is a cultural and collective construct which has long historical half-life and is typically difficult to articulate by individual participants of the activity system. The object determines the horizon of possible goals and actions. (Y. Engeström et al., 2002a, pp. 214-215)

\footnotetext{
${ }^{4}$ For recent more detailed presentations of the method of the Change Laboratory, see Y. Engestöm (2007) and Virkkunen (2006).
} 
Discussions in the Change Laboratory are crucial for participants to recognize their motives and the object of their activity.

According to Leont'ev (1978), meaning exists only in relation with personal sense, which connects it with the reality of the individual's own life and motives.

Psychologically, in the system of the consciousness of the subject and not as its object or product, meanings generally do not exist except in realizing one sense or another, just as the subject's actions and operations do not exist except as realizing one or another of his activities aroused by a motive or a need. (p. 93)

In other words, to reach meaning the individual has to develop his or her own personal sense of a given object, and this process is always indirect and mediated. Quoting Leont'ev again,

Embodying sense in meaning is a deeply intimate, psychologically meaningful process not in the least automatic or momentary .... Scientific psychology knows this process only in its partial expression: in the phenomena of "rationalization" by people of their actual motives, in experiencing the torment of transition from the thought to the word (L. S. Vygotsky quotes Tyutchev: "I forgot the word which I wanted to say, and the thought, lacking material form, will return to the chamber of shadows"). (p. 93)

The elaboration of personal sense can be a laborious and painful process for which material support is necessary. For Leont'ev (1978) this contact between the internal and the external world is mediated by interpersonal communication:

The life of the individual does not "speak for itself," that is, the individual does not have his own language with meanings developed within it; perception by him of phenomena of reality may take place only through his assimilation of externally "ready" meanings - meanings, perceptions, views that he obtains from contact with one or another form of individual or mass communication. (p. 93)

The dramatic effect of internal movements in the individual

is created by senses that cannot express themselves in adequate meanings, senses that have lost their real life basis and for this reason sometimes agonizingly discredit themselves in the consciousness of the subject; it is created finally by the existence of motives-goals conflicting with one another. (p. 94)

Discursive analyses of the use of language in Change Laboratory sessions should make explicit different participants' personal senses and the conflicting motives and goals with which they are associated.

This internal movement of individual consciousness has its origins in the movement of objective activity of man, ... behind its dramatic effects hide the dramatic effects of his real life, ... for this reason scientific psychology of consciousness is not possible outside the investigation of the activity of the subject, the forms of its direct existence. (p. 94)

In other words, the investigator's search for the participant's personal sense becomes legitimate in connection with the actual activity in which the participant is involved.

Also, Leont'ev (1978) mentions explicitly the function of experiences in this process of elaboration of personal sense and involvement in a given activity: 
The experiences, ... although they seem to be internal forces moving through his activity, their real function is only leading the subject to their real source in that they signal the personal sense of events taking place in his life, they make him seem to stop the flow of his activity for an instant to contemplate the life values he has constructed in order to find himself in them, or perhaps to review them. (p. 95)

Leont'ev goes as far as affirming that the participant's elaboration of personal sense can be the result of the researcher's work: "Before and within the analysis, the subject appears only as some kind of abstraction, a psychologically "unfulfilled" whole. Only as a result of the steps taken by research does the subject disclose himself, concretely - psychologically, as a person" (p. 95). In this light, the Change Laboratory may be seen as an indirect process that mediates the development of the participants' personal sense of the activity they are involved in. This process is initiated and sustained by the researchers' intervention.

The concept of personal sense has strong implications for the practice of the Change Laboratory. This concept provides a means to establish connections between local interactions during the research intervention sessions and the overall transformations of professional practices. Participants who reconceptualize the object of their work in Change Laboratory see the object through the perspective of their own motives, that is, in the perspective of personal sense. The development of personal sense is a critical achievement that allows participants in Change Laboratories to envision and implement change in their work. The methodological procedure of the intervention, the use of artifacts such as the three sets of surfaces, and the discussions within the Change Laboratory mediate the process through which participants elaborate their personal sense of the object.

\section{EXPERIENCING AS CONNECTING FACTOR BETWEEN TALK AND ACTION}

Existing analyses of discourse within Change Laboratory draw mainly on Bakhtin's (1984) polyphonic approach to the use of language. In spite of the valuable and rich perspective Bakhtin offers to detect multiple voices in the discourse, this theoretical view does not seem sufficient for investigating how talk leads one to act in a certain way within an activity.

Bakhtin, as a philosopher and literary scholar, developed his notion of dialogism within the fields of philosophy of language and rhetorical theory. His analysis of Dostoyevsky's novels led to the development of a number of concepts that have become very influential in activitytheoretical analyses of discourse (see, e.g., R. Engeström, 1995; Wertsch, 1991). Polyphony is one of these concepts. It implies that individual discourse and thinking are never isolated because they are constantly influenced by others and constantly interact with other people's discourse. Although with Bakhtin, and authors such as R. Engeström and Wertsch, one can observe how individual speech and collective discourse are saturated by multiple voices in the course of Change Laboratory discussions, it remains unclear how talk is experienced within the interactions during the interventions. In particular, I am interested in the way participants

\footnotetext{
${ }^{5}$ Experience is a central concept for Dewey (e.g., 1938). A separate analysis would be required to identify commonalities and differences between Leont'ev's activity-theoretical notion of experiencing and the Deweyan notion of experience.
} 
experience of collective discussions in the Change Laboratory leads them to act to promote or to resist change.

For this purpose, I use interlocutionary logic, which is a pragmatic approach to the study of the use of language in conversations. It is originally based on a revised version of speech act theory (Austin, 1962) and developed since the 1970s by the French psychologist Alain Trognon. ${ }^{6}$ Speech acts are the acts performed by speakers by means of their talk. Speech acts are characterized by an illocutionary force $(F)$ and a propositional content $(p)$. The force is the pragmatic function of the talk. Speakers can perform a number of actions through their speech. They can assert, ask, commit, declare, and express feelings. The propositional contents are the cognitive aspect of speech acts, that is, the representations they convey. Interlocutionary logic identifies the pragmatic and cognitive functions of speech acts by the way speech acts are exchanged and affect individuals' talk through the subsequent speaking turns in a conversation. Interlocutionary logic identifies the functions of speech acts by observing them in the prospective and retrospective dynamics they are involved in conversation. In other words, interlocutionary logic focuses on the way individual talk is elaborated in the course of the interlocution.

Interlocutionary logic alone would not allow me to pursue the aim of this article because it is primarily meant to analyze transcribable conversational sequences and the way interlocutors reach, or do not reach, mutual understanding. I believe, instead, that the way a conversation develops and an activity is carried out through conversations cannot be revealed only by analyzing how talk is interpreted by the interlocutors but rather by focusing on how talk is experienced by them. Our interpretations are determined by our experiences, but the role that the latter play in conversation is underscrutinized. Within activity theory, Vasilyuk's (1988) concept of experiencing is a foundational theoretical intermediate concept for the analysis of discourse by interlocutors in research interventions. The term experiencing refers to a process through which an individual, supported by others, is engaged in a quest to overcome critical situations. I consider experiencing as the connecting factor between ongoing conversations and future-oriented actions.

A theoretically grounded use of the concepts of experience and experiencing is far from consolidated. Experience is rather a fashionable term, which is almost systematically employed relying on its everyday meaning. A number of recent books on experience lack clear definitions of the term (e.g., Ankersmit, 2005; Middleton \& Brown, 2005). As Jay (2005) pointed out, the term experience has rarely been defined and explicated as a concept. Major attempts to conceptualize experience can be found in cognitive science (Varela, Thompson, \& Rosch, 1991), in psychology (Csikszentmihalyi \& Csikszentmihalyi, 1988), and in psychotherapy in the work of Vasilyuk (1988).

According to Vasilyuk (1988), experiencing is an activity organized with the explicit aim to work out critical conflicts and to restore individual internal necessities. By critical conflicts Vasilyuk referred to situations in which people face inner doubts that paralyze them in front of contradictions between motives unsolvable by the participant alone: "Experiencing is the response to a situation of impossibility or unintelligibility" (p. 199). A successful psychotherapeutic process is an example of experiencing. In the following section, I discuss experiencing

\footnotetext{
${ }^{6}$ For more detailed information on interlocutionary logic and its general theoretical framework, see Trognon (1999) and Sannino (2006).
} 
as a process that creates favorable circumstances for individuals to engage in processes of transformation and innovation.

\section{EXPERIENCING AS PREPARATION FOR THE INDIVIDUAL TO ACT}

Although Vasiliuk's concept of experiencing has been developed and used so far only within psychotherapeutic practice, experiencing as a phenomenon is not exclusively confined within the context of psychotherapy. Experiencing is the fundamental process through which human beings cope with problems and change in different circumstances in their lives. The advantage of studying experiencing as it occurs in psychotherapeutic sessions is that the work of the therapist with the patient openly materializes experiencing. The patient and therapist jointly work at identifying and overcoming sources of discomfort in the patient's life. Within research intervention sessions such as those of the Change Laboratory, experiencing occurs when a participant is brought to reflect on his or her own work situation and on the possibility to change it. $^{7}$

The process of experiencing does not lead the participant directly to realize his or her needs. It leads to restoring the psychological possibilities to carry on the activity required for the realization of these needs. In other words, experiencing may be seen as a process through which individual disposition to act is prepared. Vasilyuk (1988) exemplifies this feature of experiencing by reporting the case of one of the patients in his psychotherapeutic practice:

A woman patient of ours, N. L., sent to us by the medical officer of a department for treatment of neuroses for psychological counseling, complained of inability to solve her family problems. Her husband had forbidden N.L. to see her mother. The patient nevertheless continued to meet the mother, and suffered guilt feelings towards her owing to the need for secrecy, and feelings of fear (of her husband) in case the concealment came to light. Analysis of the patient's life situation showed that N. L. was attempting to behave as if her life-world was simple: she behaved to her mother as though the husband's ban did not exist, and to her husband as though there were no secret meetings with her mother. In other words, N. L. was avoiding internal conflicts as such, was afraid of taking the responsibility of letting these two life relations confront one another in her consciousness: ... she had not been able to stand up to her husband regarding the value (not just the importance) to her of her own mother, while betrayal of that value was making her feel that she was disintegrating as a personality (and was on her own admission corrupting the integrity of her children by obtaining them to lie to their father). The counseling resulted in N. L. gaining a clear-cut, conscious recognition of the value involved, and an understanding of the need to defend it and embody it in real behavior .... The important part of this story for us is that experiencing, in the shape of value-development of consciousness, did not in itself solve the patient's life problems, but it did transform a conflict that was causing torment owing to its insolubility into a complication of life, itself far from simple, but potentially resolvable and therefore no longer causing psychotrauma. The experiencing did not make the choice, it made choice subjectively possible. (pp. 195-196)

To understand this passage from Vasilyuk, it is important to highlight two key concepts in his theory: the concept of life-world and the concept of value.

\footnotetext{
${ }^{7}$ For further analysis of the process of experiencing in nontherapeutic contexts, see a case study in which experiencing is analyzed as it occurs within interventions at a university (Sannino, 2005).
} 
Life-world is a concept often used in phenomenologically oriented studies (Schutz \& Luckmann, 1973) to refer to the intersubjective world of everyday life that individuals take systematically for granted without reflecting on it. Vasilyuk's concept of life-world differs from this.

For Vasilyuk (1988), life-worlds are peculiar forms of life in which participants are involved. Vasilyuk constructs a typology of life-worlds based on the characteristics of simplicity-ease and the opposite, complexity-difficulty. This typology creates two pairs of opposite categories: simple-complex and easy-difficult. The pair simple-complex refers to the participant's internal world, whereas the pair easy-difficult refers to the participant's external world. This typology is used by Vasilyuk to depict conflictual movements within the process of experiencing, as in the case of the patient in the quote. According to Vasilyuk, the process of experiencing holds life together "against the various destructive and disintegrating forces which attack it in a difficult and complex world" (p. 129). The patient in the quote had built a representation of her life situation based on simplicity in her own internal world and difficulty in the circumstances in which she was living and that she perceived as complex. This led her to surrender in front of the conflict and to search for easy ways out of the situation.

The concept of life-world is the primary ontology within Vasilyuk's theory of experiencing. He considered it as the starting point for psychological inquiries, because when the researcher looks at

a particular activity as the "unit of life" for a person, then the object of that activity appears, in this abstracted form, not in its own self-sufficiency and self-identity, not as a thing representing itself, but as a unit representing the life-world, and it is by virtue of this representative character that the object acquires the status of a motive. (p. 103)

Vasilyuk built the ontology of the life-world on Leont'ev's assumption that the object is the motive of the activity and on Marx's logic of ascending from the abstract to the concrete.

To base a psychological theory on the statement that the object is the motive of activity is to start from the conviction that life is ultimately determined by the world. At this initial stage of theoretical construction there is no differentiation of actual functions performed by the motive (stimulation of activity, direction of activity, formation of meaning), we are not yet speaking of the various forms of ideational mediations involved in the initiation and regulation of concrete activity on the part of an actual, concrete person- that will all transpire later, that is not what we start from but what we will come to, "ascending" from the abstract to the concrete. (p. 103)

For the purpose of the analysis in this article these considerations of the connection between object and motive within the ontology of life-world are fundamental because the transformative potential of an activity lies in its object being the motive of the activity itself. To activate this transformative potential of the activity through research, our interventions must be based on an ontology of life-world as well. This requires that we engage first in elaborating the abstract representation of the activity in which one is involved in as unit of life for the participant, that is, as a unit of analysis that is abstractly recognized as "source of contents" (p. 103) for the individual living in particular circumstances. Only later this preliminary work develops into concrete design of tools for mediating the practical transformation of the activity.

Value is one of the principles that regulate the process of experiencing. The other principles are pleasure, reality, and creation. Value is "the supreme principle of the complex-and-easy 
life-world" (Vasilyuk, 1988, p. 138). This principle allows the participant to cope with the pain of having to compare significant different motives and to make choices in life.

\begin{abstract}
All the meaning of life is concentrated in the value. ... For a person "taken over" by a higher spiritual value, choice ceases to be an urgent problem, for he has, as it were, made his choice once and for all .... Value lights up the whole life of a human being from within, filling it with simplicity and true freedom-freedom from hesitation and fear, freedom to fulfill creative capabilities. (pp. 141-142)
\end{abstract}

The principle of pleasure is dominant in the easy-simple life-world, if it would be possible to build and live this kind of life. The principle of reality is the law to which the difficult-complex life-world is subordinated; it is the essential condition for existence and self-preservation in this kind of life. The principle of creation is the synthesis of the three others. It refers to human beings who are actively working on themselves and dealing with conflictual motives for building up their lives.

Among these four principles, the principle of creation is particularly important not only because it synthesizes the three others but also because the process of experiencing is a creative process in itself. According to Vasilyuk, experiencing as a creative process, because of its composite nature of multiple principles, is also exposed to risks and tensions.

The ... creative process of experiencing ... is itself far from harmonious. Each of the life principles-pleasure, reality, and value - ... represents such a powerful and independent force, and their aims in the given situation may be so much at variance, that grave inner conflicts between principles can occur during the experiencing process. These conflicts are often resolved only inadequately and one-sidedly. Although temporary, partial restoration of harmony to consciousness and personality may be achieved, overall the solution of such conflict may have negative results as destructive to the personality as the actual events being experienced. Thus experiencing can often be a prolonged, chain-reaction type of process, at each successive stage of which one has to deal not only, or not so much, with the original critical circumstances as with the unfortunate consequences of foregoing attempts to cope with those circumstances. (p. 171)

Individuals renew themselves by working out their conflicts through this very uneven process of experiencing. Through these risks and tensions, the process of experiencing also opens up possibilities for the individuals to internalize contradictory motives at the level of their professional activity. The process of experiencing is situated at the intersection of conflicts and contradictions. Conflicts relate to personal and interpersonal crises, whereas contradictions relate to systemic tensions within an activity and/or between multiple activities:

There is a substantial difference between conflict experiences and developmentally significant contradictions. The first are situated at the level of short-time action, the second are situated at the level of activity and inter-activity, and have a much longer life cycle. They are located at two different levels of analysis. The roots of the conflicts can be explored only shifting from the action level of conflict to the activity level of contradiction. (Sannino, 2005, p. 169) 


\section{DATA FROM A CHANGE LABORATORY DISCUSSION}

The data I analyze in this article have been collected during Change Laboratory sessions in a Finnish middle school. These data are of particular interest because through the interventions, the teachers designed and implemented durable innovations in the instructional practices of their school. One of these innovations concerned what the teachers called the "Final Project," a special optional assignment they introduced in the curriculum for students in the final grades of the school.

As this article is a methodological article, the empirical analysis proposed here is only an example aimed at showing the potential of the concept of experiencing for fulfilling the purpose of Change Laboratories and for further developments of this method. The analysis is therefore not a full-scale empirical analysis of the Change Laboratory conducted in the Finnish middle school. Full-scale analyses of entire Change Laboratory processes will have to be conducted in future studies.

According to Y. Engeström et al., (2002a), the teachers reconceptualized the object of their activity: They began to talk about their students as capable and smart instead of defining them as apathetic and incompetent. This reconceptualization of the object was possible because of two factors functioning as mediators. First, the material design and practical implementation of the Final Project broke several constraining boundaries of traditional school teaching. Second was the power of multivoicedness among teachers, especially the relatively new voices of teachers of immigrant students.

My analysis here purports to show that the transformative power of discourse resided not in the voices themselves but in the way voices were received and internalized through the work of experiencing while teachers were involved in the practical task of designing and implementing the Final Project.

The particular phase of the Change Laboratory from which I have taken the data for this article concerns the 11th and last session of the first cycle of the Change Laboratory in the middle school. In this session, the teachers, meeting all together but representing several working groups, presented and discussed their ideas for experimentation with new solutions to the school's problems. The excerpt on which the analysis in this article focuses involves teachers who were members of Group 2, which generated the idea of the Final Project and was subsequently responsible for its implementation in the entire school.

The Final Project was a special assignment that students in the 9th and 10th grades could choose to work on. This special assignment required that the student chose a topic among a list of topics or suggested a topic of his or her own, to work on for the whole spring semester under the supervision of a teacher assigned to him or her. The Final Project was not necessarily meant to be a written document; it could be any kind of product of legitimate work, to give the students a chance to express freely their own interests and special skills and to give a chance to the teachers to become better acquainted with the students. By successfully completing a good quality Final Project, a student could improve his or her grade in the relevant subject or get a mention for the Final Project in the middle school diploma. At the end of the school year the Final Projects were to be collected and displayed in a public exhibition in the school.

Besides the teachers of the Group 2, other teachers from the school took part in the Change Laboratory session. In addition to the teachers, a researcher-interventionist, the principal of the school, and a representative of the City Board of Education participated in the discussion. The 
principal of the school participated in every session of the Change Laboratory and originally was a strong proponent of the Change Laboratory in his school. The representative of the City Board of Education was present in this session because her office funded the Change Laboratory research project and she wanted to evaluate and comment on the results reached so far.

The next excerpt is translated from Finnish. Although this excerpt is taken from the last session of the first cycle of the Change Laboratory, when the participants were finalizing their ideas about the changes they wanted to test and implement in their practices, it contains an interesting debate about the inclusion of the immigrant students in the implementation of the Final Project. Group 2 had excluded the immigrant students from their plan because most immigrant students were studying in special classes and, in spite of their age, were not able to formally complete the academic requirements of the Finnish middle school.

This school had separate classes for immigrant students who had recently moved to Finland and do not know enough, or any, Finnish; thus, they could not be directly integrated into regular Finnish-speaking classes. These immigrant students' classes were therefore temporary classes where they were taught either in their native language, or in both Finnish and in their native language. In this excerpt, immigrant students' teachers take strong agentive action to get their students included in the implementation of the Final Project. The expression "agentive action" refers to specific types of talk that are strictly related to the interlocutors' practice of teaching. Through these types of talk teachers commit to implementing the Final Project in their classes and assess this innovation as feasible on the basis of similar assignments they have previously used with their students. The turn numbers refer to the turns of the meeting segment devoted to discussion of the Final Project.

\section{SESSION 11 OF THE CHANGE LABORATORY}

13 Representative of the City Board of Education: I would ask another question. It occurred to me when I thought about the different student groups, the immigrant students. Is it the intention that also they will do the final project? Those who are about to complete their comprehensive school? Have you thought about this? In their own native language?

14 Interventionist: Has the group thought about this?

15 Teacher 5 (member of Group 2): No. This is for ninth-graders and tenth-graders.

16 Teacher 6 (immigrant students' teacher): I already quite personally thought that at least my class will do this, in one way or another. We can take into account students' special skills in this project. There are such skills which are not so academic, but there are many such domains of know-how that are extremely important.

17 Representative of the City Board of Education: I would imagine that this project is particularly suitable for these students.

18 Interventionist: As you can see, these plans can have many problems as they progress and they need to be followed up all through the spring semester.

19 Teacher 7 (a second immigrant students' teacher): Me for example, about two weeks ago I gave to my students a similar kind of project assignment. And they must complete it by Christmas. It is not so long as this one. It is just five pages on any topic. They can use pictures, whatever. Whether they are in the right age so that this job is appropriate for them, I will see that in practice.

20 Interventionist: You will get a foretaste. 
21 Teacher 7: Yeah, the day after tomorrow we will see (laughing).

22 Interventionist: Good.

23 Teacher 8 (a third immigrant students' teacher): We have had something similar for Russian immigrant students. They had to do it in Finnish.

24 Teacher 7: I gave them permission to do it in their own native language. They don't have the necessary skills in Finnish language. They will get stuck if that is required.

25 Teacher 8: Their language skill is weak.

26 Teacher 7: The whole energy goes into translation.

27 Unidentified participant: Are these...?

28 Interventionist: You can make a plan for making a dress and the text you can write in Russian or Finnish. But which language is emphasized here is probably very dependent on the concrete group and concrete individual. So I am sure this group will have to think about this more.

29 Representative of the City Board of Education: One more question. If the topic is, let's say, making a dress. Is the content the actual dress, making the dress, or actually a description of the process of the work of making the dress? If it is a description then it will yield many kinds of descriptions. They can be in any language.

30 Principal of the school: Chairman (referring to the interventionist), may I intervene and say that if a final project is done, it must be done in Finnish, if it is not just a literary product. Our emphasis also for immigrant students is to learn Finnish. That is the starting point. If they use such written expression as work descriptions or similar things, then that has to be produced in Finnish. This is what I wanted to say. No other comments.

31 Interventionist: Well, how their work becomes translated into Finnish, that can happen in many ways. So it is not necessarily so that they have to write in one hour an essay in Finnish, right (laughing).

32 Teacher 10: I believe that if a foreign student is very interested in his or her own topic he or she may actually find more Finnish words, in a burst of enthusiasm. Motivation may become very big for that. So this may also help them learn Finnish much more than otherwise.

33 Interventionist: Yes.

34 Teacher 8: A couple of years ago we had a boy who knew very poorly Finnish. He was so interested in topics in Finnish history. He used a lot of energy to translate from a Russian book a multiple-page section into Finnish.

35 Teacher 6: They all did a small final project. I have done this two years ago. They were ten to fifteen pages long, pretty big. They were handwritten texts, though. And they were asked to choose topics about Finland or anything, whatever they are interested in. It was pretty good. Mistakes were abundant. I don't give a damn for the mistakes. They did the final project. I did not mean that it would have to be written in their own native language. But the supervising teacher is there in order to help.

36 Interventionist: This suggestion also includes the idea that the final projects are displayed at the end of the semester. Isn't that right? Good.

37 Representative of the City Board of Education: Yes, a comment. The first group topic was traditions. Well, this is also related to it because this will become a new tradition. 
The 9th grade mentioned in Turn 15 is the final grade of the comprehensive school; however, in many comprehensive schools in Finland there is a 10th grade as a "second final grade" for those students who choose to have a complementary year before going to high school. These are students who feel they did not do very well with their final grades and they need another year to prepare before trying to get into senior high school. This particular middle school in which the data have been collected has a large 10th-grade class.

This final session of the Change Laboratory took place just before Christmas, on the 16th of December. Teacher 7 in Turn 21 is referring to the last day of school before the Christmas break, when the students had to return the assignment.

\section{ANALYSIS OF EXPERIENCING}

The excerpt from the discussion in the Change Laboratory presents two interesting types of talk. On one hand, there is talk through which participants commit to engage practically in the ongoing process of innovation. On the other hand, there is talk through which participants relate to previous concrete experiences in their teaching practice. I call both these types of talks agentive because they are both firmly connected to the participants' action.

In the terminology of interlocutionary logic, the talk through which participants commit to something practical belongs to commissive speech acts. This is, by definition, agentive talk: The speaker expresses his or her intention to act in a specified way. Teachers 6 and 7 use this type of talk: I already quite personally thought that at least my class will do this, in one way or another (Teacher 6, Turn 16); also, I will see that in practice (Teacher 7, Turn 19). Teacher 6 commits to involve her class of immigrant students in the new practice of the Final Project. The teacher expresses this commitment by emphasizing her determination to pursue it (Turn 16: ... at least my class will do this, in one way or another). Teacher 7 takes up an ongoing experimentation in his class, which involves the students in project assignments similar to the Final Project (Turn 19: ... about two weeks ago I gave to my students a similar kind of project assignment). The teacher commits to using this ongoing experimentation in his class as a practical test to verify if this kind of assignment is appropriate for his students (Turn 19: ... Whether they are in the right age so that this job is appropriate for them, I will see that in practice).

By taking up this ongoing experimentation the commitment of Teacher 7 is grounded in the concrete life of his class. Teacher 7's commitment therefore is a step forward in the process of involving the immigrant students in the Final Project, compared with the more general commitment of Teacher 6 .

These agentive turns of talk of Teachers 6 and 7 evolve through prospective and retrospective dynamics of the conversation in the section of the excerpt from Turns 19 to 22 . The commitments expressed in Turns 16 and 19 are reinforced by the interlocutors in the subsequent speaking turns, specifically in Turn 17 of the representative of the City Board of Education and in Turns 20 and 22 of the interventionist. The representative of the City Board of Education expresses her opinion on the Final Project as "particularly suitable" (Turn 17) for the immigrant students. In Turn 20 the interventionist refers to Teacher 7's commitment as allowing to "get a foretaste" of the Final Project in the teacher's own ongoing experimentation. Turn 22 by the interventionist is an explicit positive remark on the teacher's commitment. 
The commitments appear intertwined in a collective texture of reciprocal discursive support. This collective dimension transpires also if we compare the formulation of Teacher 7's commitment in Turns 19 and 21. In Turn 19 the teacher says "I will see," whereas in Turn 21 he says "we will see." In the movement from one speaking turn to another, the teacher transforms his personal commitment into a joint commitment.

The talk through which participants relate to previous concrete experiences has also an agentive connotation. This talk confirms the possibility of making concretely the changes discussed in the session. This type of talk conveys that similar changes as those discussed in the session have been made previously in the teaching practice of some participants, therefore the changes discussed are doable: Me for example, about two weeks ago I gave to my students a similar kind of project assignment (Teacher 7, Turn 19). We have had something similar for Russian immigrant students (Teacher 8, Turn 23). He used a lot of energy to translate from a Russian book a multiple-page section into Finnish (Teacher 8, Turn 34). Finally, and most forcefully: They all did a small final project. I have done this two years ago. They were ten to fifteen pages long, pretty big. They were handwritten texts, though. And they were asked to choose topics about Finland or anything, whatever they are interested in. It was pretty good. Mistakes were abundant. I don't give a damn for the mistakes. They did the final project (Teacher 6, Turn 35).

Through the two types of talk the immigrant students' teachers were embodying personal sense in the object - the immigrant students - that had been invested by their colleagues with a meaning which did not correspond to the reality of their teaching in the immigrant classes and to their motives. Teachers'commitments and reports of previous successful experiences signaled their personal sense of the immigrant students' ability to deal with these kinds of tasks. The emergence of personal sense and of the teachers' commitments were supported by other interlocutors, in particular by the representative of the City Board of Education and by the interventionist. Moreover, the three teachers of immigrant students together produced something that resembles Vasilyuk's "chain-reaction type of process" of experiencing, only not within a single individual but distributed among the three teachers building on one another's agentive utterances.

Two restrictive representations emerge from the data. One representation transpires from the talk of Teacher 5 who speaks on behalf of Group 2 (Turn 15: No. This is for ninth-graders and tenth-graders). The simple "No" made clear the assumed weakness of the immigrant students. The other representation was made explicit by the principal and concerned the obligatory use of Finnish language (Turn 30).

The immigrant students' teachers responded to the first restrictive representation by using the two types of agentive talks just discussed. They overcame this first representation by openly challenging the group. On one hand, they directly dismantled the representation of the immigrant students' weakness by committing to involve their immigrant students in the implementation of the Final Project. On the other hand, by referring to previous experiences, they showed that immigrant students are up the challenge of working on this kind of assignments.

The second restrictive representation, which concerned the obligatory use of Finnish language, was not tackled directly as the teachers did with the first one. Although the first representation was highlighted by other teachers, who had an equal status in the school, the second representation came from the principal of the school, who had power and authority over the teachers. The teachers could not overcome this second representation the same way they 
did with the previous one. The interaction stimulated by the principal's strict declaration of the need to use exclusively Finnish language in the Final Project includes interesting and subtle agentive features. The principal's talk in itself was agentive, but in an authoritative top-down way. The reactions to the principal's categorical requirement were agentive in the sense of aiming at softening up the tone of the conversation to leave space for free adjustments during the implementation of the Final Project. A process of experiencing, being a process of creation, cannot be confined within authoritative directions. The principal's talk was in that sense an attempt to contain the creative process. The participants reacted to this by purposefully making the issue fuzzy to leave space for action in the process of innovation: Well, how their work becomes translated into Finnish, that can happen in many ways (interventionist, Turn 31). He used a lot of energy to translate from a Russian book a multiple-page section into Finnish (Teacher 8, Turn 34). I did not mean that it would have to be written in their own native language. But the supervising teacher is there in order to help (Teacher 6, Turn 35).

The immigrant students successfully completed the final project. In one of the follow-up meetings, organized in August 1999 to assess how the innovations were introduced in the teaching practices and what results had been obtained, the immigrant students' Teacher 6 stated the following:

As I teach the immigrant kids' class, pretty much everybody, I think eight or seven out of ten students did complete the final project. I was myself surprised by how fine they actually realized that. They all did it during the textile work lessons and then also used other class hours to complete it. But anyway they actually completed them, and how fine they came out! I had much bigger doubts about it initially.... And of course we have to remember that it was pretty much a handicraft work, that project. I could not require that they use very much text, not very much written explanation about how they did it, because it would have taken a tremendous amount of time. But the results, they were for me a big positive surprise.

The students of this particular teacher were predominantly Somali girls whose literacy skills were very limited even in their own native language.

The use of commissive speech acts and the recurrent reference to past successful experiences by the immigrant students' teachers are particularly interesting in relation to the teachers' experience of implementing the Final Project in the immigrant classes. In the follow-up meeting, Teacher 6 acknowledged that the success of the immigrant students in the Final Project surprised her and that initially she had doubts about the possible outcome of this work by her students. In the 11th meeting of the Change Laboratory, instead, her commitment to the implementation conveyed absolute certainty that these students would indeed succeed in this assignment (Turn 16: We can take into account students' special skills in this project. There are such skills which are not so academic, but there are many such domains of know-how that are extremely important). Also, in the last meeting of the Change Laboratory, Teacher 6 supported her commitment by using arguments based on similar previous experiences (Turn 35: They all did a small final project. I have done this two years ago. They were ten to fifteen pages long, pretty big...). It seems that her talk in the last meeting of the Change Laboratory was only abstractly or anticipatorily agentive, focusing as it were on fighting the aprioristic restrictive representations brought in by the other interlocutors. In the movement from the abstract envisioning of the innovation to its concrete implementation, the actual products of the immigrant students' took her by surprise. 
Teacher 6's personal sense about her students appears in this perspective to be associated with conflicting motives and goals. On one hand, she wanted her students' own strengths to be recognized; as such, she aimed at providing them with innovative teaching which would support and develop further these qualities. On the other hand, as a teacher of immigrant students she knew the limitations of her students within the standards required by the Finnish school system, and although she concretely implemented the innovation, she also feared for failure in the face of a task possibly too demanding. The Change Laboratory opened up for this teacher a possibility to face these conflicting motives in her professional activity.

\title{
Reconceptualizing the Object Versus Reappropriating the Action
}

The analysis shows Change Laboratory as a research setting where it is possible to observe connecting threads between the way talk is experienced and the actions that individuals then take within their activities. Change Laboratory appears as a valuable opportunity to study the relation between language and activity because it promotes discussions about and engagement in transformations of the participants' practice. As Y. Engeström et al. (2002a) stated,

\begin{abstract}
The teachers' positive talk about students gained momentum only during the practical implementation of the final project. In other words, while expansive learning in this case is manifested in, and possibly carried forward through teachers' words and speech genres redefining their object (the students) as competent and energetic, it is initiated by and grounded in the practical action and material artifacts of the final project. (p. 221)
\end{abstract}

Deepening our understanding of the relation between discursive dynamics and material practices in the Change Laboratory can have important consequences on further developments of this method of intervention, for more sophisticated discourse analyses of the data, for sharpening the view on verbal exchanges while conducting this type of interventions, and for training interventionists. In light of the analyses presented in this article, research in this direction would require equipping the Change Laboratory with tools for identifying and facilitating discursive processes of experiencing. The Change Laboratory at the moment does not provide a systematic structure to generate these processes. Tools potentially useful for generating these processes in Change Laboratory exist already in another related intervention method, called Clinic of Activity (Clot, 2004). By taking up this method here, I aim to discuss a potentially complementary way to purposefully promote discursive processes of experiencing such as those illustrated in the analysis of the excerpt from the Finnish middle school.

Clinic of Activity is another interventionist approach within the broad framework of activity theory. This approach may be useful for expanding the method of Change Laboratory. Complex experiential contents are usually not spontaneously displayed in conversations. We need methodological tools as those developed in the Clinic of Activity to make these contents explicit. An integration of the Clinic of Activity in the method of the Change Laboratory would be fruitful because it would open up interesting possibilities to serve the purpose of making experiential contents explicit in the process of transforming work.

Change Laboratory is a method for reconceptualizing the object of work. The Clinic of Activity is a method that brings practitioners to reappropriate the actions they engage in at work. The integration of the two methodologies that I propose does not consist in inserting the 
procedures of the Clinic of Activity as a specific step into the process of the Change Laboratory. The integration I advocate is in itself a research project because it requires experimental working out of necessary adjustments between the two methodologies.

The Clinic of Activity developed by Yves Clot and his colleagues is an indirect method inspired by Vygotsky which focuses on the way practitioners experience the object of their work (Clot, 2004). The explicit research purpose of the Clinic of Activity is to understand and transform ordinary work activities by bringing together researchers and practitioners to share psychological analyses of work.

The interventions in Clinic of Activity are organized as dialogic frames that support debates between professionals on the basis of jointly produced cross-commentaries of videotaped images that depict daily activities at work. In the Change Laboratory cross-commentaries of videotaped material from the actual work activities in which the participants are involved are also commonly used. In the second cycle of the interventions in the middle school, for instance, these procedures were used as well:

Before the actual intervention sessions, we first videotaped lessons where teachers used information and communication technologies. After such a lesson, we asked the students and teachers (first separately, then jointly) to reflect and comment critically on the lesson-the commentaries were also videotaped. In the first laboratory sessions in the fall of 2000, the teachers watched and discussed selected excerpts from the lessons and commentaries. On the basis of these discussions, the teachers selected nine topics and formed nine groups to design new curriculum units to serve as spearheads of change. Plans for the new curriculum units were presented and discussed in sessions in the winter of 2001. The new units were implemented in the spring of 2001, and implementation lessons were again videotaped. At the end of the school year, the new units and their implementation were assessed jointly. (Y. Engeström, Engeström \& Suntio, 2002b, p. 320)

Two main differences in the technical procedures of the interventions can be immediately highlighted. One difference concerns the use of a particular technique for provoking the debates. The second difference concerns the nature of the transformations promoted by these two interventionist methodologies.

The cross-commentaries on the videotaped materials in the Clinic of Activity are based on the technique of "instructions to the ringer" (Oddone, 1981). A practitioner is asked to instruct the researcher on how to perform the practitioner's job in such a way that nobody would notice any difference in the work done. The discussions around the videotaped materials in the Change Laboratories are typically not managed according to a particular technique of interactions among the participants.

In the Clinic of Activity, after the practitioner has told the researcher how to perform his or her work tasks, the practitioner gives similar instructions to a colleague. This allows the practitioner's view on the activity to become accessible from different angles: One view is the result of the instructions that the practitioner gives to the researcher, and another view is accessible when the practitioner gives instructions to a colleague (Clot, 2004). Because the researcher does not have the same level of expertise as a colleague does, the practitioner who gives the instructions to the researcher must make explicit a number of procedures that typically remain tacit when he or she is giving instructions to a colleague.

Clot (2004) acknowledged that within these self-confrontation interactions "language is not only a means of explicating what one does or sees, but it is a means of action, a way to bring the 
other to think, to feel and to act" (p. 8). In other words, these kinds of exchanges can promote the development of agency in the interlocutors. The analysis of the way language operates as a means of acting on the interlocutor appears however only partial within the Clinic of Activity. The interlocutor's point of view remains in the shade in the analysis. Although the participant's way of experiencing the talk of the interventionist and of the colleague is acknowledged as important, the actual analyses of the Clinic of Activity do not focus on the mechanisms of experiencing. The result is that the participant's discourse develops and remains monologically isolated. In my view, this missed deepening of the analysis corresponds to a missed opportunity to connect individual experiencing of interlocution to the collective potential of transforming the activity.

The historically accumulated professional experiences of the participant are at the core of the analyses in the Clinic of Activity. Interactions between different experiences within a professional collective are considered the creative motor for developing work practices. Through the routines of ordinary work activities individual experiences tend to isolate in one-sided and limited professional views (Clot, 2004). The kind of transformation involved in the practice of the Clinic of Activity is, however, more centered on each individual involved in the intervention rather than on the professional collective as a whole. Such engagement by single individuals rarely leads to practical changes in the work of an organization. The Clinic of Activity enables practitioners to reappropriate their professional actions (Scheller, 2004). This reappropriation seems nevertheless not to lead to consistent and material transformation in the workplaces. It seems to lead the practitioners to reconceptualize their attitudes toward the object, not the object in itself.

The focus on the object itself has the power of engendering agency and actual change in work practices. Intervening on the participants' attitudes toward the object, however, is also essential for identifying critical conflicts that prevent the practitioners from engaging in creative design for transforming their work activities. In other words, these two approaches are complementary.

\section{Seeking an Historical Perspective}

There are previous analyses of the way discourse develops through Change Laboratory sessions. Y. Engeström et al.'s (2002a) analysis of the same particular Change Laboratory in the middle school I analyzed here refers to a radical change in the teacher's talk about the students. Over a period of 9 months of Change Laboratory sessions and their follow-up meetings, the overall talk of the teachers shifted from negative talk to optimistic talk about the students. A number of other papers based on the method of the Change Laboratory refer to shifts in talk as indicators of breakthroughs or turning points in the process of the intervention (e.g., Ahonen \& Virkkunen, 2003). These analyses, however, have not so far included a conceptualization on agentive talk.

In Change Laboratory the two types of talk just identified above-talk through which a participant commits to something practical and talk through which a participant relates to previous concrete experiences in his or her practice - can have a strong impact on the progress of the expansive learning cycle (Y. Engeström, 1999). The toolkit of the Change Laboratory is not at the moment specifically equipped with instruments to identify, elicit, and support these two types of talk. On the other hand, one cannot sensibly affirm that these types of talk are just fortunate accidents in Change Laboratories. Might the process of the 11 sessions itself be somehow instrumental for the participants in developing a way to report on their 
experiences of innovative teaching practice? Also, might the Change Laboratory sessions be somehow instrumental in developing agentive perspectives, which lead participants to commit to expansive initiatives in the collective endeavor? This article cannot answer these questions. Answers to these questions require longitudinal and comparative analyses of the interactions in the Change Laboratories. These questions, however, raise the issue of reconstructing the history of change efforts in various organizations and bringing an historical perspective into the analyses of the Change Laboratories as discourse- and activity-centered processes of experiencing.

Research interventions as discourse- and activity-centered processes of experiencing have to face the challenge of including historical analysis in their practice of inquiry. These kinds of analyses are already consolidated in the method of the Change Laboratory (Y. Engeström, 1993), but they generally focus on the history of institutions rather than on the practitioners' personal histories of work. Both historical perspectives are needed. The hybridization of Change Laboratory and Clinic of Activity is worth exploring as a potentially fruitful way to bring together the two historical perspectives.

From the point of view of Vasilyuk's (1988) theory of experiencing, history is an essential analytical component:

The typological analysis of experiencing has to be complemented by cultural-historical analysis aimed at elucidating the substantive regularities, expressed in specific historical terms to be found in experiencing. ... It is after all not difficult to discover the cultural-historical mediation of any human experiencing. Why, for instance, did the prisoners in Schlüsselburg fortress ... find the forced-labour situation intolerable, and only reconcile themselves to it psychologically as the result of an experiencing process which transformed the inner motivation of this alien, imposed activity, so that it was turned into something psychologically quite different - free, voluntary activity? ... One would think that for a slave in the ancient world, for instance, such a situation would not require any experiencing .... The slave was able to reconcile himself to his life situation (even if he had been born free and only later became enslaved) because there were operating within his consciousness certain "schematisms" ..., evolved on the basis of the slave-owing social formation, themselves objective and for him directly phenomenologically obvious; according to these a slave was "an animate thing only (in Roman law a slave is referred to as res, a thing), or at best a domestic animal .... Quite different schematisms define the consciousness, and the consciousness of self, of a human being in European society in modern times. In the experiencing gone through by the Schlüsselburg prisoners there is the schematism that is probably the central one for this period ... Within the field of operation of this schematism the highest value is placed upon such aspects of human life as possession of consciousness and free will, initiative, responsibility, etc.-in a word, freedom. (pp. 173-174)

Vasilyuk discussed the interconnection between interpersonal exchanges and the use of mediating tools in the analysis of experiencing.

Merely to state that experiencing processes have a historical basis is hardly the end of the matter. A psychological, properly speaking, approach to the problem would be to apply to the analysis of experiencing the general schema for all socio-historical determination of human psychology which L. S. Vygotsky and his pupils have already tried to produce, using a variety of psychological materials ...; that is, to understand experiencing as a process mediated by "psychological tools" $\ldots$ which are artificial formations, social in nature ..., taken up and internalized by the subject in the course of communication with people. (p. 174) 
This point is also where Vasilyuk's inquiry shows its limitations, recognized by the author himself.

To carry through a cultural-historical treatment of experiencing means analyzing three mutually interconnected questions: What is the nature of the specifically cultural modes of experiencing? What particular features are found in the process whereby these are acquired? And lastly, what is the nature of the part played by other people in the acquisition process and in the actual experiencing of an individual? The limits of this present work, and of the author's erudition, forbid our answering these questions fully. Their detailed investigation must be a matter for special studies. (p. 174)

This article aims at opening up the field for this type of studies.

\section{CONCLUSION}

This article focuses on the dynamics through which dialogues within Change Laboratory affect material actions in activities. I addressed two research questions by using Leont'ev's concept of personal sense and further by means of the conceptual frameworks of the theory of experiencing and of interlocutionary logic.

The first question concerns how to analyze participants' ways of articulating and reconceptualizing the object of their practice in Change Laboratory. The concept of personal sense provides an analytical lens to understand how participants in Change Laboratory come to see the object of their work practice in a new light. Although they articulate and reconceptualize their object in Change Laboratory discussions, they elaborate their personal sense of the object. Personal sense plays a foundational role in enabling participants to engage in processes of transformation of their work practice.

The second research question concerns how to conceptualize the processes through which conversations in Change Laboratory lead participants to invest with new motivation in the object of their practice. Conversations in Change Laboratory are conceptualized as experiencing. Experiencing is seen here as a discursive process through which individuals are supported to face conflicting motives and change their material circumstances. The dynamics of interlocution as exchange of linguistic acts affect participants in the Change Laboratory. The way these exchanges are experienced by the participants can be instrumental for recognizing conflicting motives and for working them out through concrete engagement in change initiatives.

The potential of concepts such as personal sense, experiencing, and interlocution was tested in an empirical analysis of an excerpt from discussions in a Change Laboratory session in a Finnish middle school. The conceptual framework allowed me to identify two types of discourse I call agentive talk because of its strong connection to the participants' material actions in changing their teaching activity. The first type of agentive talk conveys commitments from the immigrant students' teachers to implement in their classes a new form of assignment called Final Project. This talk develops as the teachers progressively ground their arguments in concrete teaching experiences. This process was supported by other interlocutors and led to the expansion of an individual commitment of one teacher into a collective commitment. The second type of talk relates more directly to previous concrete experiences in the practice of these immigrant students' teachers. Previous teaching experiences emerged as factors that 
confirmed that the changes the teachers were committing to were doable. This justifies the agentive connotation given also to the second type of talk.

The analysis of the conversation identified tensions stemming from restrictive representations of immigrant students conveyed in the talk of other participants of the Change Laboratory. Immigrant students' teachers and other participants in the intervention appeared to have conflicting motives with regard to the implementation of the Final Project. The immigrant students' teachers saw the Final Project as an opportunity for their students to use their diverse potentials. Other participants, instead, considered the Final Project as an assignment of excellence for students who wanted to take a challenge and demonstrate their literacy-based competences. The two types of agentive talk materialized discursive processes of experiencing with the help of which the immigrant students' teachers worked out these conflicting motives. The analysis identifies also individual conflicting motives transpiring from the discourse of one of the immigrant students' teachers. While trying to overcome the restrictive representations of immigrant students, this teacher was dueling between wanting to recognize the strength of these students and fearing for their failure in doing the assignment.

In the introduction I contrasted the perspective on agency developed in this article with the perspective pursued by Duranti (2007). My argument supports the view that by intervening in the development of certain type of discussions such as those that take place in Change Laboratory, it is possible to influence developmental transformations of entire activities. This article suggests that discursive agency fulfills its agentive nature by progressively transcending the situated confines of discourse and taking the form of concrete developmental actions.

What is needed in the light of this analysis is the elaboration of a theoretical and empirical framework that would allow systematically tracing discourses from the point of view of the work of experiencing done by the interlocutors. Such analyses of experiencing may open up a new understanding of processes triggered and supported by Change Laboratory.

The theory of Vasilyuk (1988) is applicable in practice to such an endeavor only through the development of an appropriate method of intervention. As Vasilyuk wrote,

\begin{abstract}
Absence of method leaves even the most coherent and well-argued theory hanging in a speculative mid-air, for method is the one and only bridge by which mutually beneficial exchanges between theory and practice can proceed. As regards a method that can adequately serve the theory of experiencing, it is quite clear that it cannot be a strictly research-oriented method, approaching its object with cognitive aims only. It has to be psycho-technical. A model of such method can be found within Soviet psychology, in P. Y. Galperin's theory of the stage-by-stage formation of mental operations, where that which is under study is treated (to use the words of Marx's famous theses) not only as an object, or as a contemplation, but as a human sensory activity, practice, in which the researcher himself is actively involved." (pp. 203-204)
\end{abstract}

The method of the Change Laboratory does not provide systematic procedures to facilitate the emergence of discursive processes of experiencing. The article highlights the complementarity between the Change Laboratory and one other interventionist method called Clinic of Activity. The fact that the technical procedures of these methods are partly similar supports the hybridization of the two approaches. Inquiries in the direction of integrating them would lead to a new type of research intervention configured as a process of experiencing which operates both discursively and in activity. Discursive resolutions of conflictual motives would be combined with design and implementation of material transformations. As Y. Engeström et al. (2002b) stated, 
these discursive expansive actions had to be accompanied by equally expansive practical actions in classrooms. The two require each other. The pulsating transitions between these different contexts of action are of crucial importance for the accomplishment of sustainable innovation from below in a school community. (p. 324)

While facilitating processes of experiencing, the emerging new type of method would also need to equip itself with tools for pursuing historical inquiries. Experiences are the substance of personally meaningful history. Experiences are also relevant for institutional history because institutions are shaped and maintained by intentional human actions. These actions need to be made visible and accountable in collective discussions within developmental interventions. Integrating the analysis of the personal in institutional histories can transcend both the limits of experience understood as strictly personal and the limits of activity understood as strictly structural.

\section{ACKNOWLEDGMENTS}

This analysis was in part made possible by a grant from the Finnish Cultural Foundation.

I warmly thank Pirjo Lambert, Ivana Marková, and Jaakko Virkkunen for their invaluable comments on an earlier version of this article. The statements in this article are, however, solely my responsibility.

\section{REFERENCES}

Ahonen, H., \& Virkkunen, J. (2003). Shared challenge for learning: Dialogue between management and front-line workers in knowledge management. International Journal of Information Technology and Management, 1, 59-84.

Ankersmit, F. R. (2005). Sublime historical experience. Stanford, CA: Stanford University Press.

Austin, J. L. (1962). How to do things with words. Cambridge, MA: Harvard University Press.

Bakhtin, M. (1984). Problems of Dostoevsky's poetics. Minneapolis: University of Minnesota Press.

Brown, A. L. (1992). Design experiments: Theoretical, and methodological challenges in creating complex interventions in classroom settings. The Journal of Learning Sciences, 2, 141-168.

Clot, Y. (2004). Le travail entre fonctionnement et développement [Work between functioning and development]. Bulletin de Psychologie, 57, 5-12.

Collins, A. (1992). Toward a design science of education. In E. Scanlon \& T. O'Shea (Eds.), New directions in educational technology (pp. 15-22). Berlin: Springer.

Csikszentmihalyi, M., \& Csikszentmihalyi, I. (1988). Optimal experience: Psychological studies of flow in consciousness. Cambridge, UK: Cambridge University Press.

Dewey, J. (1938). Experience and education. New York: Collier.

Duranti, A. (2007). Etnopragmatica: La forza nel parlare [Ethnopragmatics: The power in talk]. Roma: Carocci.

Engeström, Y. (1987). Learning by expanding: An activity-theoretical approach to developmental research. Helsinki, Finland: Orienta-Konsultit.

Engeström, Y. (1993). Developmental studies on work as a testbench of activity theory. In S. Chaiklin \& J. Lave (Eds.), Understanding practice: Perspectives on activity and context (pp. 64-103). Cambridge, UK: Cambridge University Press.

Engeström, R. (1995). Voices as communicative action. Mind, Culture, and Activity, 2, 192-215.

Engeström, Y. (1999). Innovative learning in work teams: Analyzing cycles of knowledge creation in practice. In Y. Engeström, R. Miettinen, \& R-L. Punamäki (Eds.), Perspectives on activity theory (pp. 377-404). Cambridge, UK: Cambridge University Press. 
Engeström, Y. (2007). Putting Vygotsky to work: The change laboratory as an application of double stimulation. In H. Daniels, M. Cole, \& J. V. Wertsch (Eds.), The Cambridge companion to Vygotsky (pp. 363-382). Cambridge, UK: Cambridge University Press.

Engeström, Y., Engeström, R., \& Kerosuo, H. (2003). The discursive construction of collaborative care. Applied Linguistics, 24, 286-315.

Engeström, Y., Engeström, R., \& Suntio, A. (2002a). Can a school community learn to master its own future? An activity-theoretical study of expansive learning among middle school teachers. In G. Wells \& G. Claxton (Eds.), Learning for life in the 21st century: Sociocultural perspectives on the future of education (pp. 211-224). Oxford, UK: Blackwell.

Engeström, Y., Engeström, R., \& Suntio, A. (2002b). From paralyzing myths to expansive action: Building computersupported knowledge work into the curriculum from below. In G. Stahl (Ed.), Computer support for collaborative learning: Foundations for a CSCL community (pp. 318-324). Mahwah, NJ: Erlbaum.

Engeström, Y., Lompscher, J., \& Rückriem, G. (Eds.). (2005). Putting activity theory to work: Contributions from developmental work research. Berlin: Lehmanns Media.

Hill, R., Capper, P., \& Wilson, K. (2007). Workplace learning in the New Zealand apple industry network: A new co-design method for government "peace making." Journal of Workplace Learning, 19, 359-376.

Jay, M. (2005). Songs of experience: Modern American and European variations on a universal theme. Berkeley: University of California Press.

Leont'ev, A. N. (1978). Activity, consciousness, and personality. Englewood Cliffs, NJ: Prentice-Hall.

Middleton, D., \& Brown, S. D. (2005). The social psychology of experience: Studies in remembering and forgetting. London: Sage.

Oddone, I. (1981). Redécouvrir l'expérience ouvrière [Discovering the workers' experience]. Paris: Éditions sociales.

Sannino, A. (2005). Cultural-historical and discursive tools for analyzing critical conflicts in students' development. In K. Yamazumi, Y. Engeström, \& H. Daniels (Eds.), New learning challenges: Going beyond the industrial age system of school and work (pp. 165-195). Osaka, Japan: Kansai University Press.

Sannino, A. (2006). Analyzing discontinuous speech in EU conversations: A methodological proposal. Journal of Pragmatics, 38, 543-566.

Scheller, L. (2004). Clinique de l'activité et conflits dans le travail [Clinic of activity and conflicts at work]. Bulletin de Psychologie, 57, 99-103.

Schutz, A., \& Luckmann, T. (1973). The structure of the life world. Evanston, IL: Northwestern University Press.

Trognon, A. (1999). Eléments d'analyse interlocutoire [Elements of interlocutionary analysis]. In M. Gilly, J. P. Roux, \& A. Trognon (Eds.), Apprendre dans l'interaction (pp. 69-94). Nancy, France: Presses Universitaires de Nancy.

van der Akker, J., Gravemeijer, K., McKenney, S., \& Nieveen, N. (2006). Educational design research. London: Routledge.

Varela, F. J., Thompson, E., \& Rosch, E. (1991). The embodied mind. Cambridge, MA: MIT Press.

Vasilyuk, F. (1988). The psychology of experiencing. Moscow: Progress.

Virkkunen, J. (2006). Dilemmas in building shared transformative agency. Activités, 3(1), 19-42. Retrieved from http://www.activites.org

Virkkunen, J., Engeström, Y., Helle, M., Pihlaja, J., \& Poikela, R. (1997). The change laboratory: A tool for transforming work. In T. Alasoini, M. Kyllönen, \& A. Kasvio (Eds.), Workplace innovations: A way of promoting competitiveness, welfare and employment (pp. 157-174). Helsinki, Finland: Ministry of Labour.

Vygotsky, L. S. (1978). Mind in society: The development of higher mental processes. Cambridge, MA: Harvard University Press.

Wertsch, J. V. (1991). Voices of the mind: A sociocultural approach to mediated action. Cambridge, MA: Harvard University Press. 